\title{
Comment on: "A Systematic Review of the Cost-Effectiveness of Biologics for Ulcerative Colitis"
}

\author{
Ena Singh ${ }^{1}$
}

Published online: 4 May 2018

(C) Springer International Publishing AG, part of Springer Nature 2018

Dear Editor in Chief,

As the Therapeutic Area Team Leader, Gastroenterology, for tofacitinib at Pfizer, I read with great interest the review by Drs. Stawowczyk and Kawalec entitled "A Systematic Review of the Cost-Effectiveness of Biologics for Ulcerative Colitis" [1].

First, the article contains a number of inaccuracies concerning tofacitinib that should be brought to the attention of the authors and your readers. Although tofacitinib is currently unapproved for use in ulcerative colitis (UC), it may be appropriate to compare the cost-effectiveness of tofacitinib with the existing biologic therapies used in UC; however, it is important to point out that tofacitinib is a synthetic, small molecule Janus kinase inhibitor, but has been inaccurately described as a biologic agent in the article.

Second, there appears to be some confusion within the article between the statements relating to tofacitinib approval status, in both the Introduction and the Materials and Methods sections. At present (March 2018), tofacitinib has not been approved for use in UC in either the USA or Europe, but is currently approved for the treatment of rheumatoid arthritis and psoriatic arthritis [2].

This comment refers to the article available at https://doi.org/10.1007/ s40273-017-0601-6.

Ena Singh

Ena.Singh@pfizer.com

1 Gastroenterology, Inflammation and Immunology, Medical Affairs, Pfizer Inc, 500 Arcola Rd, Collegeville, PA 19426, USA
Finally, we recently published the results from the OCTAVE Induction and Maintenance studies of tofacitinib in moderate to severe UC [3], and are nearing completion of an open-label extension study of tofacitinib in moderate to severe UC [4].

Kind regards

Ena Singh

Acknowledgements Funding was provided by Pfizer Inc.

\section{References}

1. Stawowczyk E, Kawalec P. A systematic review of the costeffectiveness of biologics for ulcerative colitis. PharmacoEconomics. 2018;36:419-34.

2. Pfizer announces FDA approval of XELJANZ ${ }^{\circledR}$ (tofacitinib) and $\mathrm{XELJANZ}^{\circledR}$ XR for the treatment of active psoriatic arthritis. http://press.pfizer.com/press-release/pfizer-announces-fda-approvalxeljanz-tofacitinib-and-xeljanz-xr-treatment-active-psor. Accessed 18 Jan 2018.

3. Sandborn WJ, Su C, Sands BE, et al. Tofacitinib as induction and maintenance therapy for ulcerative colitis. $\mathrm{N}$ Engl J Med. 2017;376:1723-36.

4. ClinicalTrials.gov. Long-term study of CP-690,550 in subjects with ulcerative colitis (OCTAVE). https://clinicaltrials.gov/ct2/ show/NCT01470612?term $=$ NCT01470612\&rank $=1$. Accessed 9 Jan 2018. 